\title{
A Rare Case Report of Trans Oral Removal of Air Gun Pellet
}

\author{
Dr. Deepu Abraham Cherian ${ }^{1 *}$, Dr. Anilkumar Peethambaran ${ }^{2}$, Dr. Sharmad M. S ${ }^{3}$
}

\author{
${ }^{1}$ Senior Resident, Department of Neurosurgery, Govt. Medical College, Trivandrum, Kerala, India \\ ${ }^{2}$ Professor and HOD, Department of Neurosurgery, Govt. Medical College, Trivandrum, Kerala, India \\ ${ }^{3}$ Addl Professor, Department of Neurosurgery, Govt. Medical College, Trivandrum, Kerala, India
}

DOI: $10.36347 /$ sjmcr.2020.v08i12.005

| Received: 26.11.2020 | Accepted: 07.12.2020 | Published: 10.12.2020

*Corresponding author: Deepu Abraham Cherian

Abstract

This is the case report of trans oral trans pharyngeal removal of air gun pellet which was accidentally fired into the mouth of a young gentleman while attempting to clean the gun. The gun pellet pierced the soft palate and dodged into the Cranio Vertebral Junction (CVJ) in the anterior aspect. Removing a foreign body dodged close to such a deep and vital area of the brain and spinal cord was a very challenging task from the part of Surgeons. The most difficult part of the whole scenario was the dilemma of whether to operate upon a patient who was totally preserved and remove a foreign body or to just observe the patient. We proceeded with the first option of surgical removal. The patient survived the surgery and was discharged without any focal neurological deficit.

Keywords: Trans pharyngeal exploration, Cranio Vertebral Junction, fire arm injury.

Copyright $(\mathcal{C} 2020$ The Author(s): This is an open-access article distributed under the terms of the Creative Commons Attribution 4.0 International License (CC BY-NC 4.0) which permits unrestricted use, distribution, and reproduction in any medium for non-commercial use provided the original author and source are credited.

\section{INTRODUCTION}

Penetrating injuries encompass a range of injuries from non-missile injuries such as knife wounds to high velocity missile injuries such as rifle shots. Unfortunately the incidence of penetrating injuries is rising due to greater access of fire arms to the civilians $[1,2]$. Anatomically $20 \%$ of injuries are reported in the cervical spine, $50 \%$ in the thoracic spine, and $30 \%$ in the lumbar spine, which partially reflects the relative lengths of the spine segments [3, 4]. Approximately $40 \%$ of patients are shot in the back, while $19 \%$ are shot anteriorly. The majority of treatment recommendations are from knowledge gained from the battlefield. Low velocity injuries result in localized injury related to direct trauma without the concussive element as seen in a supersonic ballistic missile. Surgical decision making revolves around risk-benefit analysis, weighing potential gains in neurologic function against surgical risk in patients who may improve with conservative management alone.

\section{Case Report}

A 24 yr old gentleman accidentally got shot in mouth while attempting to clean his air gun upside down. He was suddenly rushed to our hospital where he was evaluated and investigations were sent as an emergency. He was fully conscious, alert, with no evidence of weakness / spinal cord injury and pharyngeal insufficiency. There was an entry wound seen in soft palate of $0.3 \times 0.3 \mathrm{~cm}$ in size and $\mathrm{x}$ ray taken showed a metallic object in front of occipital skull base near to foramen magnum. The patient underwent further evaluation by CT skull base and CVJ which confirmed the position of metallic object in front of foramen magnum.

The case was discussed in detail with the relatives and after getting informed consent we decided to proceed with the surgery rather than just observing him recognizing that the decision is like the sword of damocles. He under went transpharyngeal exploration of foreign body under fluoroscopic guidance through posterior pharyngeal wall. A $0.4 \times 0.6 \times 1 \mathrm{~cm}$ conical metallic object (air gun pellet) was obtained which was seen entrapped within posterior pharyngel musculature underneath the mucosa.

The wound was closed primarily and Ryles tube feeding was given for three days. Local wound care was continued and he was started on oral soft diet from day 3 onwards. The patient did not have any focal neurological deficit other than trivial pharyngeal insufficiency in the initial days of surgery which had recovered completely in the following days. 


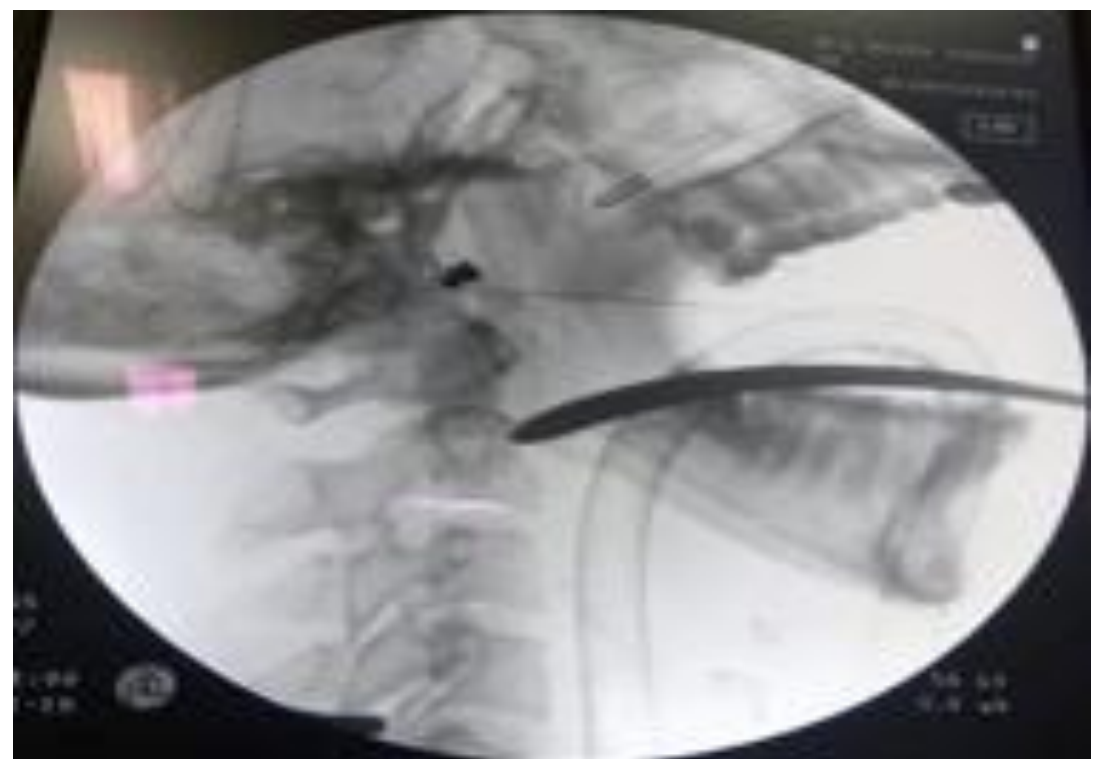

Fig-1: Showing intra op fluoroscopy with foreign body marked with a pointer

\section{DiscusSION}

Gun shot wounds especially civilian house hold fire arm injuries are in a rising trend because of increased availability and legalization. Mortality and morbidity with penetrating injuries mainly depend on the kinetic energy of the projectile, proximity to the vital structures and the range of fire arm injury. In the majority of patients suffering from penetrating spine injury, conservative (nonoperative) treatment is indicated. Historically, surgical indications included decompression and debridement of neural tissue, removal of bony or metallic fragments, dural repair required, correction of spinal instability, and relief of pain. Currently absolute indications are limited to spinal instability, intractable CSF leak and demonstration of a projectile bone fragment or hematoma that result in ongoing deficit or pain.

Once the patient has undergone a thorough evaluation, operative versus conservative management is decided on a case by case basis. The main factors influencing this decision are the extent of neural element compression and the patient's potential for functional neurologic recovery.

The degree of neurologic compromise and potential for functional recovery is important in determining the aggressiveness of treatment. In patients who are neurologically alright local wound care alone may be adequate.

The majority of penetrating injuries require only nonsurgical management. In such cases, local wound care and supportive care are sufficient. The wound should be thoroughly cleaned and followed up closely for signs of CSF leak or infection especially if a dural injury has occurred. In addition, prophylactic antibiotics should be given for 24 to 48 hours once the wound has stopped draining. Use of steroids in penetrating spinal injuries are controversial. Although benefit has been seen in closed Spinal cord injuries, penetrating spinal injuries patients were excluded from the National Spinal Cord Injury Study II which makes it difficult to draw a definite conclusion [5].

Outcome following surgical interventions depend mainly on the extend of trauma and manipulation done and the edema and injury to the neighboring neurovascular structures. The decompression should be undertaken once a potential complication of neurovascular complication is anticipated in the near future.

Once the location and proximity to the nearby structures are in doubt, radiological evaluation and intra op fluoroscopic guidance can be great use and help. Pinpointing the object to the minutest extend will ensure better post operative outcome. The mode of approach to the foreign body should be clearly sorted out to avoid unpleasant surprises during the venture.

\section{Conclusion}

Firearm injuries, especially civilian firearm injuries are one of the rare penetrating injuries, even though its numbers are rising now. We present here a case of air gun pellet injury, which penetrated the pharyngeal musculature and dodged deep into the anterior aspect of foramen magnum, which was successfully removed by a trans oral approach without causing any significant post operative neurological deficiency.

\section{REFERENCES}

1. Bahebeck J, Atangana R, Mboudou E, Nonga BN, Sosso M, Malonga E. Incidence, case-fatality rate and clinical pattern of firearm injuries in two cities where arm owning is forbidden. Injury. 2005 Jun 
$1 ; 36(6): 714-7$

2. Benzel EC, Hadden TA, Coleman JE. Civilian gunshot wounds to the spinal cord and cauda equina. Neurosurgery. 1987 Feb 1;20(2):281-5.

3. Shahlaie K, Chang DJ, Anderson JT. Nonmissile penetrating spinal injury: case report and review of the literature. Journal of Neurosurgery: Spine. 2006 May 1;4(5):400-8.

4. Klein Y, Cohn SM, Soffer D, Lynn M, Shaw CM,
Hasharoni A. Spine injuries are common among asymptomatic patients after gunshot wounds. Journal of Trauma and Acute Care Surgery. 2005 Apr 1;58(4):833-6.

5. Vanderlan WB, Tew BE, Seguin CY, Mata MM, Yang JJ, Horst HM, Obeid FN, McSwain NE. Neurologic sequelae of penetrating cervical trauma. Spine. 2009 Nov 15;34(24):2646-53. 